\title{
The Arbitrary Coherence Effect and Decision Making
}

\author{
Michael D. Mattei \\ Bellarmine University \\ Stephen J. Hellebusch \\ Hellebusch Research \& Consulting
}

In Behavioral Economics, "arbitrary coherence" is when an arbitrary, randomly chosen number, influences the amount purchasers are willing to pay for a product. Arbitrary coherence is similar to anchoring which marketers sometimes use to help set optimal prices. This paper examines how the arbitrary coherence effect influences individual decision making.

Keywords: arbitrary coherence, anchoring, new product pricing, purchase intent

\section{INTRODUCTION}

A landmark article in Science (Tversky and Kahneman, 1974) reported a research track concerning decision-making that essentially created the field of Behavioral Economics. In that article, the authors noted that humans normally use heuristics ("rules of thumb") to interpret information and make decisions. Humans are especially prone to errors concerning representivity (judging instances more or less representative than they are; ignoring sample size, etc.), availability (e.g., bias of imaginability), and adjustment and anchoring (e.g., bias due to conjunctive and disjunctive events).

In the book Predictably Irrational by Dan Ariely (2008), a study is described which reveals something very interesting about the effect of context on how we make decisions. Knowledgeable and very intelligent people who were fully aware that certain numbers were chosen in a completely arbitrary, random fashion were still influenced by those numbers when making decisions about what they would pay for certain items. This phenomenon is described as "arbitrary coherence", a term also found in the behavioral economics literature. One of the authors was working for a large national marketing research firm at the time and thought that the results of the study could provide a valuable tool for marketing research professionals especially in the area of setting new product prices.

A first attempt at replicating the Ariely study using four different products confirmed the phenomenon. A second study, with different items, completely failed to replicate the effect. Thus, began a nearly ten-year journey into answering the question, "When and under what conditions does the arbitrary coherence phenomenon manifest itself?" This paper details five studies beginning with the one that replicated Ariely's findings and the second study that did not demonstrate the effect. Three follow-up studies with students and national samples are described in an effort to identify the underlying factors when arbitrary coherence is observed and when it is not. 


\section{LITERATURE REVIEW}

Beyond the landmark article in Science (Tversky and Kahneman, 1974), the book Thinking, Fast and Slow (Kahneman, 2011) elaborated on forty years of research in the area by describing two mental "systems." Kahneman appropriately cautions that thinking is not as simple as the two-system concept suggests, but the theory helps understand and describe the findings. System 1 is the heuristic-using operator that relies on bits of available data and draws conclusions; it is very good at perceiving patterns, even where there are none. System 2 is the thinking component - focus, concentration, work. System 1 only examines and operates on what is present. Kahneman summarizes its method with WYSIATI - an admittedly awkward acronym for "What You See Is All There Is". System 1 does not consider unseen possibilities. It makes quick, easy decisions, often accurate in everyday life.

System 2 is the analytical function. It can explore possibilities and elements that are not present, but this requires thinking, which is hard work. So, if System 1 makes a judgment and nothing present (WYSIATI) conflicts with it, System 2 will likely "rubber stamp" it, taking the easy way out. Given this, decisions are subject to systematic biases.

The specific instance of bias of interest here is "arbitrary coherence." In a summary of six experiments, Ariely, Loewenstein, and Prelec (2003) describe an anchoring phenomenon wherein a random, arbitrary number that respondents know is irrelevant to the decision influenced their judgments of amounts willing to pay and reactions to hearing painful sounds. The authors' own words are the best succinct description of the phenomenon.

In six experiments, we show that the initial valuations of familiar products and some simple hedonic experiences are strongly influenced by arbitrary "anchors" (sometimes derived from a person's social security number). Because subsequent valuations are also coherent with respect to salient differences in perceived quality or quantity of these products and experiences, the entire pattern of valuations can easily create an illusion of order, as if it is being generated by stable underlying preferences. The experiments show that this combination of coherent arbitrariness (1) cannot be interpreted as a rational response to information, (2) does not decrease as a result of experience with a good, (3) is not necessarily reduced by market forces, and (4) is not unique to cash prices. The results imply that demand curves estimated from market data need not reveal true consumer preferences, in any normatively significant sense of the term.

The authors say this in a less precise but perhaps clearer way in their introduction.

In this paper, we show that consumers' absolute valuation of experience goods is surprisingly arbitrary, even under "full information" conditions. However, we also show that consumers' relative valuations of different amounts of the good appear orderly, as if supported by demand curves derived from fundamental preferences. Valuations therefore display a combination of arbitrariness and coherence that we refer to as "coherent arbitrariness."

Arbitrary coherence is also referred to in Predictably Irrational (Ariely, 2008), and is put in the broader context of anchoring in Priceless (Poundstone, 2010). The latter also points to numerous examples of anchoring and arbitrary coherence in setting market prices and determining price changes. One example is lowering the volume of peanut butter by indenting the bottom of the jar, since consumers will, by and large, fixate on the familiar price, not the volume. Once an anchor price is established, all other pricing in that particular arena can be coherent with that price in some way. Luxury goods can especially benefit from a high anchor price point.

In a literature search aimed specifically at finding work on "arbitrary coherence" only two articles specific to the topic appear. In a pilot project with 41 fourth year medical students, Pouthier (2009) found 
that having them write the last two digits of their mobile telephone numbers influenced their subsequent responses to a series of questions concerning surgical training. The questions required estimating numbers, and the mean results by student correlated $(\mathrm{r}=0.36, \mathrm{p} \leq .05)$ with the irrelevant telephone number digits. The author warns that steps should be taken to minimize this unexpected potential bias.

A second article with students at Cambridge (Scott and Lizieri, 2011) tested two hypotheses. Paraphrasing, they were (1) an arbitrary anchor will reliably influence judgment of a property's value, even when incentives are provided for accuracy; (2) subsequent judgments of property values will be influenced by the value immediately prior, so a single subject's valuation set will be coherent. After significant data manipulation ("eliminating noise") primarily by eliminating outliers, they more or less confirmed both hypotheses. Their research clearly has implications for pricing in real estate marketing.

As noted, arbitrary coherence is put into a broader context of anchoring in Priceless (Poundstone, 2010), pointing to numerous examples of anchoring and arbitrary coherence in setting market prices and determining price changes. Another example, besides the peanut butter jar, is placing a very expensive item on display, so that other items of less expense look reasonable - the $\$ 9,000$ Gucci purse displayed with many $\$ 2,500$ to $\$ 3,000$ purses available for purchase.

Fudenberg, Levine and Maniadis (2010), in "Reexamining Coherent Arbitrariness for the Evaluation of Common Goods and Simple Lotteries" found that the effects of the arbitrary coherence manipulation on the valuation of common market goods produced very weak anchoring effects, and no effects at all on the valuation of binary lotteries.

The assumption that people make decisions based on a constant set of preferences, so that choices should not depend on context-specific cues (anchors), is one of the cornerstones of economic theory. We reexamined the effects of an anchoring manipulation on the valuation of common market goods that was introduced in Ariely, Lowenstein and Prelec (2003). We found much weaker anchoring effects. We performed the same manipulation on the evaluation of binary lotteries, and we found no anchoring effects. This suggests limits on the robustness of strong anchoring effects. Hence, the evidence that people have "arbitrary preferences" may not be conclusive, and economic theory may still be valid in many cases of interest.

The experiments conducted by Fudenberg et. al. (2015) took place in the California Social Science Laboratory (CASSEL) at UCLA, in August of 2009, and the subjects were UCLA students. The first of four experiments were paper-and-pencil as was the case in Ariely et. al. and reexamined the effects of random anchors on subjects' valuation for common market goods of interest to students.

One similarity in the reviewed research and in the initial research by the authors should be noted. Nearly all were convenience samples, primarily college students, but our earliest studies included marketing researchers who were at hand and willing. The authors are not familiar with any research that attempted to show arbitrary coherence in a national, random sample. In this paper, the last two studies are national samples of 400 respondents in each study.

In an interesting precursor of arbitrary coherence, Wilson et. al. (1996) examined anchoring effects to determine conditions under which anchoring appears. The authors supported a number of hypotheses that relate to arbitrary coherence. Each of their five studies required numerical responses. They found numerical basic anchoring effects occur when uninformative numerical anchors influence judgment, even when people are not asked to compare that anchor to the target value.

Based on the finding from their second study, Wilson et. al. eliminated any subject claiming to be knowledgeable from the next three, so their conclusions must be qualified accordingly. Wilson et. al. focused on aspects of the conditions where anchoring impacts decisions. Following Wilson et. al., questions abound about the limitations of both anchoring and the arbitrary coherence effect.

The fourth study detailed here explores the differences in perceptions which might account for when the arbitrary coherence effect is observed by using semantic differentials, specifically, do differences in the perceptions of each item tested correlate in any way to the existence or lack of arbitrary coherence? 
There is a wealth of literature on semantic differentials and the research is beyond the scope of this paper. One of the earliest publications was by Charles Osgood et. al. (1957). The fifth study detailed here returns to one of Ariely's original items, but with a national sample of 400 respondents. This last study investigates applying the arbitrary coherence effect to new product pricing.

\section{FIVE STUDIES EXAMINING THE IMPACT OF ARBITRARY COHERENCE ON DECISION MAKING}

\section{Study \#1 (AC1) - The Initial Attempt to Replicate Ariely's "Coherent Arbitrariness"}

In the Ariely study (Ariely, 2003), six items with an average retail price of $\$ 70$ were shown to 55 MBA students during the first marketing research class meeting at the MIT Sloan School. Students were asked if they would buy each item for the dollar figure equal to the last two digits of their Social Security Number. They were then asked if an auction was held, what is the highest price they would be willing to pay (WTP) for each item.

The goal of the first study we conducted was to see if the arbitrary coherence (AC) effect would be observed in a less "naïve" group of respondents. Four items were selected at random from advertisements in a Sunday paper, specifically: Teleflora Spring Pitcher Floral Display, Dr. Scholl's Hand-Stitched Leather Loafers, Irish Spring 12-bar Value Pack and a bottle of Bailey's Irish Crème (Appendix 1). There are a few differences from Ariely's original research, specifically, this study was conducted with 69 marketing research professionals and four items were tested using photos only, not the actual items. To further test the effect, two items with generally unknown values were tested with two items with generally known values below $\$ 30$. The results from Ariely are shown in Table 1 as the reference for our first study (AC1).

Our survey contained the following three questions (Appendix 2):

1. Enter the last two digits of your Social Security number (SS\#) as if it were a price in dollars.

2. Indicate if you would be willing to pay that amount for the item by writing in a Y for "yes" or an $\mathrm{N}$ for "no".

3. Pretend there is an auction for the item. In whole dollars, write in the maximum amount you would be willing to pay for it (WTP).

TABLE 1

RESULTS FROM ARIELY

\begin{tabular}{|c|c|c|c|c|c|c|}
\hline Products & Quintile 1 & Quintile 2 & Quintile 3 & Quintile 4 & Quintile 5 & \begin{tabular}{c} 
Correlation \\
\hline $\begin{array}{c}\text { Cordless } \\
\text { Trackball }\end{array}$
\end{tabular} \\
\hline $\begin{array}{c}\text { Cordless } \\
\text { Keyboard }\end{array}$ & $\$ 16.09$ & $\$ 11.82$ & $\$ 13.45$ & $\$ 21.18$ & $\$ 26.18$ & $\begin{array}{c}.415 \\
\mathrm{p}=.0015\end{array}$ \\
\hline Average Wine & $\$ 8.64$ & $\$ 14.45$ & $\$ 12.55$ & $\$ 15.45$ & $\$ 27.91$ & $\begin{array}{c}.516 \\
\mathrm{p}<.0001\end{array}$ \\
\hline Rare Wine & $\$ 11.73$ & $\$ 22.45$ & $\$ 18.09$ & $\$ 24.55$ & $\$ 37.55$ & $\begin{array}{c}.328 \\
\mathrm{p}=.014\end{array}$ \\
\hline Design Book & $\$ 12.82$ & $\$ 16.18$ & $\$ 15.82$ & $\$ 19.27$ & $\$ 30.00$ & $\begin{array}{c}.3153 \\
\mathrm{p}=.0172\end{array}$ \\
\hline $\begin{array}{c}\text { Belgian } \\
\text { Chocolates }\end{array}$ & $\$ 9.55$ & $\$ 10.64$ & $\$ 12.45$ & $\$ 13.27$ & $\$ 20.64$ & $\begin{array}{c}.419 \\
\mathrm{p}=.0013\end{array}$ \\
\hline
\end{tabular}


As Ariely (2003) points out,

... the impact of the social security number on stated WTP was significant in every product category... the top quintile subjects were willing to pay \$56 on average for the cordless computer keyboard, compared with \$16 on average for the subjects with the bottom quartile numbers. Alongside this volatility of absolute preference, we also observed a marked stability of relative preference. For example, the vast majority of subjects (>95 percent) valued a cordless keyboard more than a trackball, and the highly rated wine more than the lower-rated wine.

The results of AC1 are shown in Table 2. The arbitrary coherence effect was found to exist for the two higher-priced items where the actual price was uncertain. Even though most respondents would have a good idea of the actual retail price for the Bailey's Irish Crème there was a positive correlation. As expected, there was no correlation for the Irish Spring, the one item most subjects knew was inexpensive.

TABLE 2

RESULTS OF ARBITRARY COHERENCE (AC1) STUDY

\begin{tabular}{|c|c|c|c|c|c|}
\hline & \multicolumn{4}{|c|}{ Last 2 Digits Social Security Number as $\$$} & \\
\hline Products & Under $\$ 25$ & $\$ 26-\$ 50$ & $\$ 51-\$ 75$ & $\$ 76+$ & Correlation \\
\hline Teleflora & $\$ 22.13$ & $\$ 43.29$ & $\$ 38.70$ & $\$ 40.79$ & $+.33^{*}$ \\
\hline Dr. Scholl's & $\$ 34.13$ & $\$ 34.07$ & $\$ 49.45$ & $\$ 51.53$ & $+.28^{*}$ \\
\hline Bailey's Irish Crème & $\$ 15.50$ & $\$ 16.93$ & $\$ 16.75$ & $\$ 20.42$ & +.16 \\
\hline Irish Spring 12 Pack & $\$ 5.63$ & $\$ 9.50$ & $\$ 6.10$ & $\$ 6.21$ & -.05 \\
\hline
\end{tabular}

$*=$ the correlation is statistically significantly different than zero, $\mathrm{p} \leq 0.05$.

If a group of professionals were "impacted" by the random number anchoring, the next question was, "Is there something in the questions that produces the results?" A second study was conducted about six months later with the same, but larger group of 84 professionals.

\section{Study \#2 (AC2) - Different Item Set, Two Questions Versus Three}

For the second study, four different items, all of reasonable and unknown value, were used: Crocodile Wallet, Copper Bowl, Necklace of Pearls from Tahiti, The Complete Works of Lewis Carroll (Appendix $3)$. These were again selected from newspaper ads, this time to have prices that would likely be unfamiliar to subjects, since uncertainty is a precondition.

In this study (AC2) half the group were not exposed to the middle question "indicate if you would be willing to pay that amount for the item" (Appendix 4). The other half of the respondents completed all three of the original questions. Subjects were randomly assigned, so that half were asked the original three questions, and half were not asked the middle question (would they buy it for the specified amount). 
TABLE 3

RESULTS OF AC 2 STUDY WITH PURCHASE DECISION QUESTION (THREE QUESTIONS)

\begin{tabular}{|c|c|c|c|c|c|}
\hline & \multicolumn{4}{|c|}{ Last 2 Digits Social Security Number as $\$$} & \\
\hline Products & Under $\$ 40$ & $\$ 40$ to $\$ 59$ & $\$ 60$ to $\$ 79$ & $\$ 80$ to $\$ 99$ & Correlation \\
\hline Crocodile Wallet & $\$ 38.22$ & $\$ 42.50$ & $\$ 18.60$ & $\$ 22.69$ & -.24 \\
\hline Copper Bowl & $\$ 90.56$ & $\$ 112.90$ & $\$ 158.40$ & $\$ 151.54$ & +.10 \\
\hline Necklace from Tahiti & $\$ 26.33$ & $\$ 45.80$ & $\$ 25.50$ & $\$ 47.85$ & +.12 \\
\hline Complete L. Carroll & $\$ 65.56$ & $\$ 34.20$ & $\$ 25.50$ & $\$ 75.38$ & -.03 \\
\hline
\end{tabular}

TABLE 4

RESULTS OF AC2 WITH NO PURCHASE DECISION QUESTION (TWO QUESTIONS)

\begin{tabular}{|c|c|c|c|c|c|}
\hline & \multicolumn{4}{|c|}{ Last 2 Digits Social Security Number as $\$$} & \\
\hline Products & $\$ 0$ to $\$ 30$ & $\$ 30-\$ 59$ & $\$ 60-\$ 79$ & $\$ 80-\$ 99$ & Correlation \\
\hline Crocodile Wallet & $\$ 13.10$ & $\$ 20.22$ & $\$ 23.17$ & $\$ 20.64$ & +.08 \\
\hline Copper Bowl & $\$ 161.50$ & $\$ 189.89$ & $\$ 117.58$ & $\$ 135.45$ & -.05 \\
\hline Necklace from Tahiti & $\$ 14.10$ & $\$ 36.00$ & $\$ 36.58$ & $\$ 15.91$ & +.04 \\
\hline Complete L. Carroll & $\$ 137.10$ & $\$ 97.44$ & $\$ 95.00$ & $\$ 64.36$ & -.18 \\
\hline
\end{tabular}

In the second study, there was no arbitrary coherence effect in either subgroup. This lack of effect meant that it was impossible to shed light on the effect of the second question. It also raised new questions about the limitations of arbitrary coherence.

Did the lack of effect in the test cell that received exactly the same questions occur because the same subjects were used? But prior research, reported in Priceless (Poundstone, 2010), found that experience did not impact arbitrary coherence. In this case, though, one wonders if these informed researchers were "conditioned?" Alternatively, did the lack occur because of the items used? Were the items of little interest, limiting the effect? Or, was it just the random assignment of subjects presenting an effect of its own?

\section{Study \#3 (AC3) - Two Items Sets and Two Versus Three Questions}

The third study was conducted among 84 university students to attempt to resolve the questions from AC2; specifically:

1. Is the arbitrary coherence effect present when each set of items is tested with naïve subjects?

2. Is making a purchase decision ("the middle question") causing a different effect?

3. Is there an interaction, such that making or not making a purchase decision yields different results for each set of items?

The age range for respondents was 18 to 47 years old and all had Social Security numbers. The mean age is 22 and the median is 21 with $71 \%$ between 18 and 22 years old. Thirty-two (38\%) are female. There are 53 undergraduates $(63 \%)$ and $31(37 \%)$ graduate students.

Since there are two types of questionnaires, one with two questions and the other with three questions and two sets of items there were four test groups (Table 5). Four color coded surveys were created and distributed to four independent groups with between 19 and 22 different students per group. Group 3 (16) and Group 4 (14) contained almost all of the graduate students. 
TABLE 5

TABLE OF GROUPINGS FOR THE THIRD AC STUDY (AC3)

\begin{tabular}{|c|c|c|c|}
\hline & Item Set \#1: & Item Set \#2: & Totals \\
\hline $\begin{array}{c}\text { Purchase Decision } \\
\text { (3Qs) }\end{array}$ & $\begin{array}{c}\text { Group 1: 22 students } \\
\text { AC3, Set 1, 3Qs }\end{array}$ & $\begin{array}{c}\text { Group 3: 19 students } \\
\text { AC3, Set 2, 3Qs }\end{array}$ & 41 \\
\hline No Purchase & Group 2: 21 students & Group 4: 22 students \\
Decision (2Qs) & AC3, Set 1, 2Qs & 43 & 43 Set 2, 2Qs \\
\hline Totals & 43 & 41 & \\
\hline
\end{tabular}

Item Set \#1 consists of three of the four original items from the first study. In deference to the fact that some subjects were underage for alcohol consumption, the original Bailey's Irish Crème was changed to "Sandy Flats Pure Maple Syrup - 250ml" (Appendix 1). Item Set \#2 is the same four items used in the second study (Appendix 3). To conduct the survey a one-page paper questionnaire, color-coded by cell, was handed out for subjects to complete. A picture of each item was projected on a screen all at one time. Half the students in the room received the two-question survey and the other half received the threequestion survey.

For each item, the amount subjects were Willing to Pay (WTP) was examined in two different ways: by quartile grouping and by looking at the correlation between the SS\$ and the WTP. If arbitrary coherence holds, the WTP should increase with increasing SS\$.

\section{Group 1 - Item Set 1 and 3 Qs Plus Comparison to AC1}

Group 1 shows a clear arbitrary coherence effect. The pattern parallels the original AC1 study. The Irish Spring 12-pack of bar soap shows stronger tendency to arbitrary coherence than it did in the first study, but the correlation is still not statistically significant. Teleflora, which had the strongest correlation with the older researchers is somewhat weaker with these younger students.

TABLE 6

\section{GROUP 1: ITEM SET 1 WITH PURCHASE DECISION QUESTION PLUS COMPARISON TO AC2}

\begin{tabular}{|c|c|c|c|c|c|c|}
\hline & \multicolumn{4}{|c|}{ Last 2 Digits Social Security Number as $\$$} & \multirow[b]{2}{*}{ AC3-3Qs Correl. } & \multirow[b]{2}{*}{$\begin{array}{c}\text { AC1-3Qs } \\
\text { Correl. }\end{array}$} \\
\hline & $\$ 0$ to $\$ 25$ & $\$ 26-\$ 59$ & $\$ 60-\$ 80$ & $\$ 80+$ & & \\
\hline Teleflora & $\$ 15.83$ & $\$ 25.50$ & $\$ 22.00$ & $\$ 25.00$ & +.28 & $+.33 *$ \\
\hline Dr. Scholl's Loafers & $\$ 39.83$ & $\$ 43.83$ & $\$ 67.00$ & $\$ 56.80$ & $+.36 * *$ & $+.28 *$ \\
\hline Maple Syrup-250ml & $\$ 5.17$ & $\$ 5.50$ & $\$ 10.00$ & $\$ 23.60$ & $+.39 * *$ & $\mathrm{n} / \mathrm{a}$ \\
\hline Irish Spring 12 pack & $\$ 8.00$ & $\$ 10.00$ & $\$ 11.80$ & $\$ 10.80$ & +.24 & -.05 \\
\hline Bailey's Irish Cream & $\mathrm{n} / \mathrm{a}$ & $\mathrm{n} / \mathrm{a}$ & $\mathrm{n} / \mathrm{a}$ & $\mathrm{n} / \mathrm{a}$ & $\mathrm{n} / \mathrm{a}$ & +.16 \\
\hline
\end{tabular}

$*=$ the correlation is statistically significantly different than zero, $\mathrm{p} \leq 0.05$.

$* *=$ the correlation is statistically significantly different than zero, $\mathrm{p} \leq 0.10$.

One question this research addressed was whether results would be replicated with new subjects. They were. The respondents in the AC1 study were experienced marketing researchers, which may explain why the results with the more naïve students are overall stronger. The researchers not only were older, but also had more experience with questionnaire studies like this, which may have made them slightly less susceptible to the AC effect. 
Group 2 - Item Set 1 with No Purchase Decision Question (No Prior Study for Comparison)

While there was a clear effect with all four products when questioning with the three questions on Item Set 1 (Table 6), the arbitrary coherence effect vanishes in all but one item when the Purchase Decision Question is removed (Table 7). Teleflora has a statistically significant correlation while the effect is almost nonexistent for the other three items.

\section{TABLE 7 \\ GROUP 2, ITEM SET 1 WITH NO PURCHASE DECISION QUESTION (NO COMPARABLE PRIOR STUDY)}

\begin{tabular}{|c|c|c|c|c|c|}
\hline & \multicolumn{4}{|c|}{ Last 2 Digits Social Security Number as $\$(S S \$)$} & \\
\hline & Under $\$ 18$ & $\$ 19$ to $\$ 41$ & $\$ 42$ to $\$ 79$ & $\$ 80$ to $\$ 99$ & Correlation \\
\hline Teleflora & $\$ 6.67$ & $\$ 23.00$ & $\$ 8.60$ & $\$ 26.40$ & $+.41 *$ \\
\hline Dr. Scholl's loafers & $\$ 31.67$ & $\$ 45.00$ & $\$ 39.40$ & $\$ 40.80$ & +.07 \\
\hline Maple Syrup-250ml & $\$ 6.67$ & $\$ 9.20$ & $\$ 3.80$ & $\$ 7.00$ & +.02 \\
\hline Irish Spring 12-pack & $\$ 5.83$ & $\$ 9.00$ & $\$ 5.60$ & $\$ 6.20$ & -.04 \\
\hline
\end{tabular}

$*=$ the correlation is statistically significantly different than zero, $\mathrm{p} \leq 0.05$.

Group 3 - Item Set 2 with $3 Q$ s Plus Comparison to AC2

The student survey results for the second set of products and three questions are similar to the AC2 results; there was no arbitrary coherence effect. All the correlations are weak and three of four are negative. There is little consistency in WTP across the quartiles.

TABLE 8

\section{GROUP 3, ITEM SET 2 WITH PURCHASE DECISION QUESTION PLUS COMPARISON TO AC2}

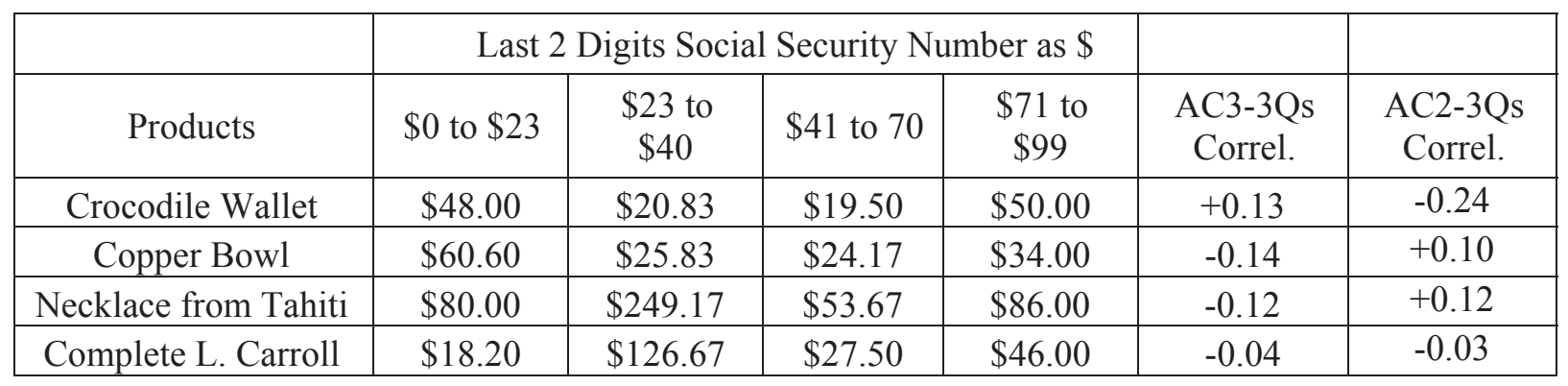

Group 4 - Item Set 2 and 2Qs Plus Comparison to AC1

Given that there was no effect with these items when a SS\$ purchase decision is required, it is not surprising that there is none when there is no purchase decision. With correlations hovering near zero, the pattern is consistent with that found with Group 2, Item Set 1 with No Purchase Decision. 
TABLE 9

\section{GROUP 4, ITEM SET 2 WITH NO PURCHASE DECISION QUESTION} PLUS, COMPARISON TO AC2

\begin{tabular}{|c|c|c|c|c|c|c|}
\hline & \multicolumn{2}{|c|}{ Last 2 Digits Social Security Number as $\$$} & & \\
\hline Products & Under $\$ 25$ & $\$ 26-\$ 60$ & $\$ 61-\$ 70$ & $\$ 71-\$ 99$ & Correl. & $\begin{array}{c}\text { AC2-2Qs } \\
\text { Correl. }\end{array}$ \\
\hline Crocodile Wallet & $\$ 40.00$ & $\$ 26.00$ & $\$ 50.00$ & $\$ 33.00$ & +0.05 & +0.08 \\
\hline Copper Bowl & $\$ 27.00$ & $\$ 20.00$ & $\$ 16.25$ & $\$ 24.00$ & -0.05 & -0.05 \\
\hline Necklace from Tahiti & $\$ 128.00$ & $\$ 71.00$ & $\$ 128.75$ & $\$ 153.00$ & +0.04 & +0.04 \\
\hline Complete L. Carroll & $\$ 22.00$ & $\$ 15.00$ & $\$ 22.50$ & $\$ 51.00$ & +0.17 & -0.18 \\
\hline
\end{tabular}

Observations and Summary of Results for AC3

In the Purchase Decision groups, an indicator of the willingness to buy is how many said "yes" to the second question, "In column B, indicate if you would be willing to pay that amount for the item." How do the proportions saying "yes" compare between this study and the earlier studies?

In Item Set 1, the overall interest in either Bailey's Irish Crème or Maple Syrup is low, as is interest in the Irish Spring soap. The interest among the AC3 students in Teleflora is not much higher than for the Irish Spring. About the only consistency is that the Dr. Scholl's loafers received more interest among the students than the researchers, and the correlation with SS\$ is stronger with students than with researchers.

TABLE 10

ITEM SET 1 - PERCENT WHO WOULD BUY PRODUCT FOR SS\$

\begin{tabular}{|c|c|c|}
\hline Items & AC2 researchers & AC3 students \\
\hline Bases & 69 & 22 \\
\hline Teleflora & $43.5 \%$ & $18.2 \%$ \\
\hline Dr. Scholl & $49.3 \%$ & $63.6 \%$ \\
\hline Bailey's/Maple Syrup & $18.8 \%$ & $9.1 \%$ \\
\hline Irish Spring & $4.3 \%$ & $13.6 \%$ \\
\hline
\end{tabular}

Interestingly, the percentages who would buy for the SS\$ prices are very similar for Item Set 2 (Table 11). In neither study with Item Set 2 was there an arbitrary coherence effect.

TABLE 11

ITEM SET 2 - PERCENT WHO WOULD BUY PRODUCT FOR SS\$

\begin{tabular}{|c|c|c|}
\hline Items & AC2 researchers & AC3 students \\
\hline Bases & 42 & 22 \\
\hline Wallet & $21.4 \%$ & $22.7 \%$ \\
\hline Bowl & $38.1 \%$ & $45.5 \%$ \\
\hline Pearl Necklace & $85.7 \%$ & $86.4 \%$ \\
\hline Carroll Book & $38.1 \%$ & $31.8 \%$ \\
\hline
\end{tabular}

Overall, there does not appear to be a strong relationship between interest and the presence of arbitrary coherence. Research Questions Answered: 
1. Is the Arbitrary Coherence effect present when each set of items is tested with naïve subjects? No. It is present in Item Set 1 in three of the items with the researchers and, to some extent, with all four among the students. But it is not present anywhere with the products in Item Set 2 , even though the actual cost of these is likely uncertain and, as nearly as can be assessed, levels of interest are similar.

2. Does making a purchase decision causes a different effect?

The similarities in the AC2 study and groups 2 and 4 in the AC3 study (where no purchase decision was made) certainly suggest that eliminating the purchase decision eliminates arbitrary coherence.

3. Is there an interaction, such that the making or not making of a purchase decision yields different results for each set of items?

This seems to be the case. Making a purchase decision is in some way responsible for creating arbitrary coherence in Item Set 1, as the comparison between Group 1 (Item Set 1 with Purchase Decision) and Group 2 (Item Set 1 with No Purchase Decision) demonstrates. But the situation is more complex, since Groups 3 and 4 show the same "no arbitrary coherence" results regardless of the inclusion of the purchase decision question.

One of the original intentions of AC3 was to see if the AC effect existed with Group 3 (Set 2, with purchase decision question), which would imply that the prior failure to replicate was because knowledgeable subjects were used in that research. The AC2 group's greater experience was obviously not the reason for the lack of effect. It also appears unlikely that lack of interest in Item Set 2 products is responsible. If it is not simply greater variability in interest, what it is about Item Set 2 that obliterates arbitrary coherence?

\section{Study \#4 (AC4) - National Sample, Two Items Sets and Two Versus Three Questions}

This study attempts to identify the underlying factors that explain why arbitrary coherence is found in some of the previously mentioned situations but not in others. Factors tested in this study were, would a national sample, rather than a local convenience sample, make a difference? Also, what would happen if each item was presented alone, not in any set? Could respondents' perception of the test items help explain when arbitrary coherence is observed? A semantic differential measurement was included in the survey to quantify factors that might be causal in producing the inconsistencies reported in the literature.

This study was conducted with a nationally representative sample of 402 adults with the objective of determining if a national sample provides more consistent evidence of arbitrary coherence than found in the literature. The eight items from the prior studies were used for this study.

The arbitrary coherence part of the questionnaire for this research was like that used in prior research. However, experience had determined that asking consumers in an online panel anything about their Social Security number reduced response rates. To compensate for this, the first question, which established the arbitrary anchor, was changed to write the last two digits of your primary telephone number as if it were a price in dollars. The first four items were in the original Item Set 1 and the last 4 items were in Item Set 2 as shown in Table 12. 
TABLE 12

BASE SIZES OF THE ARBITRARY COHERENCE TEST CELLS

\begin{tabular}{|c|c|}
\hline The Eight Item Cells & $\begin{array}{c}\text { Base: } \\
\text { Total per Cell }\end{array}$ \\
\hline Teleflora & 50 \\
\hline Dr. Scholl's Loafers & 51 \\
\hline Maple Syrup-250ml & 51 \\
\hline Irish Spring 12-pack & 50 \\
\hline Crocodile Wallet & 50 \\
\hline Copper Bowl & 50 \\
\hline Necklace from Tahiti & 50 \\
\hline Complete Works of L. Carroll & 50 \\
\hline
\end{tabular}

The Semantic Differential attributes were added after the arbitrary coherence questions for each item. They were taken from a University of California Davis teaching website (Unknown 2017). The respondent saw the semantic differential scale shown in Figure 1. After examining the connotative meaning of thousands of concepts, Charles Osgood and his associates identified three major dimensions of meaning: strength, value, and activity. The first and fifth items represent strength; the second and fourth represent value; the third and sixth represent activity.

\section{FIGURE 1 SEMANTIC DIFFERENTIAL ATTRIBUTE QUESTIONS}

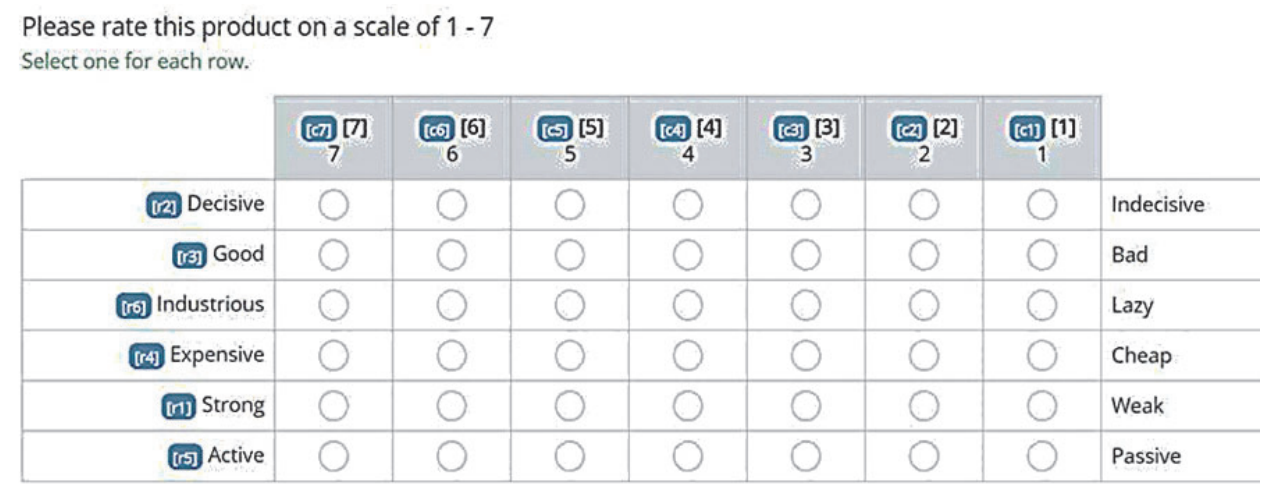

Discussion of the Arbitrary Coherence Effect

When these eight items are tested individually online with a sample national in scope, arbitrary coherence is greatly lessened. For only two of the eight items is there a clear statistically significant correlation $(\mathrm{p} \leq 0.05)$ between the last two-digit telephone dollars (\$Phone\#) and the amount respondents were willing to pay for the item, namely the Teleflora Flowers and the Crocodile Wallet. Note that arbitrary coherence was not seen with the Wallet in the second and third studies. The Pearl Necklace from Tahiti shows a directionally large correlation, but the correlation is weak for four of the other five items: Dr. Scholl's Loafers, Sandy Flats Maple Syrup, Irish Spring Soap, and the Copper Bowl. It is modest for the Lewis Carroll Book.

For five of the items, the highest \$Phone\# group has a WTP that is greater than the lowest - Teleflora, Soap, Wallet, Necklace, and Book. For the other three (Scholl's, Syrup, Bowl) the highest \$Phone\# subgroups will pay less than the lowest $\$$ Phone\# would be willing to pay. 
TABLE 13

ARBITRARY COHERENCE: WTP BY QUARTILE, CORRELATIONS

\begin{tabular}{|c|c|c|c|c|c|}
\hline & \multicolumn{4}{|c|}{$\$$ Phone\# } & \\
\hline & $\begin{array}{c}\$ 0 \text { to } \\
\$ 25\end{array}$ & $\begin{array}{c}\$ 26 \text { to } \\
\$ 50\end{array}$ & $\begin{array}{c}\$ 51 \text { to } \\
\$ 75\end{array}$ & $\begin{array}{c}\$ 76 \text { to } \\
\$ 99\end{array}$ & $\begin{array}{c}\$ \text { Phone\# } \\
\text { WTP } \\
\text { Correlation }\end{array}$ \\
\hline Teleflora & $\$ 11.16$ & $\$ 22.47$ & $\$ 27.75$ & $\$ 39.12$ & $+0.36^{*}$ \\
\hline Scholl's & $\$ 41.67$ & $\$ 50.33$ & $\$ 44.58$ & $\$ 38.38$ & -0.01 \\
\hline Syrup & $\$ 20.82$ & $\$ 14.86$ & $\$ 11.42$ & $\$ 19.07$ & -0.11 \\
\hline Soap & $\$ 6.33$ & $\$ 9.83$ & $\$ 9.84$ & $\$ 7.69$ & +0.03 \\
\hline Wallet & $\$ 8.00$ & $\$ 26.19$ & $\$ 21.53$ & $\$ 40.00$ & $+0.29^{*}$ \\
\hline Bowl & $\$ 18.00$ & $\$ 17.21$ & $\$ 27.22$ & $\$ 16.73$ & -0.01 \\
\hline Necklace & $\$ 31.00$ & $\$ 59.09$ & $\$ 56.83$ & $\$ 78.80$ & $+0.26^{* *}$ \\
\hline Carroll Bk & $\$ 9.43$ & $\$ 10.63$ & $\$ 32.67$ & $\$ 16.15$ & +0.19 \\
\hline
\end{tabular}

$*=$ the correlation is statistically significantly different than zero, $\mathrm{p}<0.05$.

$* *=$ the correlation is statistically significantly different than zero, $\mathrm{p} \leq 0.10$.

A summary of the correlations from the four arbitrary coherence studies is shown below. Up to this point, items were always tested in sets. This study (AC4) is the only study in which the context was the single item. In all, there are 24 instances where arbitrary coherence might manifest; it is clearly evident in four of the 24 , and possibly present in a total of seven of 24 instances.

TABLE 14

SUMMARY OF CORRELATIONS FROM FOUR ARBITRARY COHERENCE STUDIES

\begin{tabular}{|c|c|c|c|c|}
\hline & AC1 & AC2 & AC3 & AC4 \\
\hline Item Set 1 & & & & \\
\hline Teleflora & $0.33^{*}$ & na & 0.28 & $0.36^{*}$ \\
\hline Scholl's & $0.28^{*}$ & na & $0.36^{* *}$ & -0.01 \\
\hline Bailey's/Syrup & 0.16 & na & $0.39^{* *}$ & -0.11 \\
\hline Soap & 0.05 & na & 0.24 & 0.03 \\
\hline Item Set 2 & & & & \\
\hline Wallet & na & -0.24 & 0.13 & $0.29^{*}$ \\
\hline Bowl & na & 0.10 & -0.14 & -0.01 \\
\hline Necklace & na & 0.12 & -0.12 & $0.26^{* *}$ \\
\hline Carroll Bk & na & -0.03 & -0.04 & 0.19 \\
\hline
\end{tabular}

na $=$ Not Available.

$*=$ the correlation is statistically significantly different than zero, $\mathrm{p} \leq 0.05$.

$* *=$ the correlation is statistically significantly different than zero, $\mathrm{p} \leq 0.10$.

Since arbitrary coherence is a sub-category of the well-known anchoring effect, data were examined across all four studies to see if the highest quartile gave a higher WTP than the lowest. This did occur in 19 of 24 instances. Three that did not are in the current study (AC4). One caution is that base sizes per quartile are small. In many of the earlier studies (and in a few instances here, in AC4) they are singledigits.

Even with one of the three items (Scholl's, Syrup, Bowl) that show a negative shift in WTP from the highest to the lowest quartile in AC4, two show evidence of some anchoring effect. With Scholl's, the 
lowest shift, from Quartile 1: $\$ 0-\$ 25$ to Quartile 2: $\$ 26-\$ 50$, shows an anchoring effect, going from $\$ 41.67$ to $\$ 50.33$, but the higher levels cancel any coherence effect. There is no anchoring effect at all, even at lowest-to-second lowest quartile for Syrup or the Bowl.

In the third study (AC3), there was directional evidence of arbitrary coherence with two of the eight items. Observationally, there is at least a modest anchoring effect evident in all four Set 1 items. In Set 2, with the Wallet and the Necklace, anchoring is again very modest, but at least possibly present. With the Bowl, there is no anchoring and no arbitrary coherence in AC3.

Only Set 2 items were used in the second study and no arbitrary coherence effect was found anywhere. There does appear to be some anchoring effect; even with the Wallet the WTP goes from $\$ 38.22$ to $\$ 42.50$ in going from the Quartile 1 to Quartile 2.

TABLE 15

DIFFERENCE IN WTP, QUARTILE 4 (HIGHEST) MINUS QUARTILE 1 (LOWEST)

\begin{tabular}{|c|c|c|c|c|}
\hline & $\mathrm{AC} 1$ & $\mathrm{AC} 2$ & $\mathrm{AC} 3$ & $\mathrm{AC} 4$ \\
\hline Item Set 1 & & & & \\
\hline Teleflora & $\$ 18.66^{*}$ & $\mathrm{na}$ & $\$ 9.17$ & $\$ 27.96^{*}$ \\
\hline Scholl's & $\$ 17.40^{*}$ & $\mathrm{na}$ & $\$ 16.97^{* *}$ & $-\$ 3.29$ \\
\hline Bailey's/Syrup & $\$ 4.92$ & $\mathrm{na}$ & $\$ 18.43^{* *}$ & $-\$ 1.75$ \\
\hline Soap & $\$ 0.58$ & $\mathrm{na}$ & $\$ 2.80$ & $\$ 1.36$ \\
\hline Item Set 2 & & & & \\
\hline Wallet & na & $-\$ 15.53$ & $\$ 2.00$ & $\$ 32.00^{*}$ \\
\hline Bowl & na & $\$ 60.98$ & -26.60 & $-\$ 1.27$ \\
\hline Necklace & na & $\$ 21.52$ & $\$ 6.00$ & $\$ 47.80^{* *}$ \\
\hline Carroll Bk & na & $\$ 9.82$ & $\$ 27.80$ & $\$ 6.72$ \\
\hline
\end{tabular}

na $=$ Not Available.

$*=$ the correlation is statistically significantly different than zero, $\mathrm{p} \leq 0.05$.

$* *=$ the correlation is statistically significantly different than zero, $\mathrm{p} \leq 0.10$.

\section{Semantic Differential Measures}

As mentioned, there are three Semantic Differential dimensions: Strong-Weak, Good-Bad, ActivePassive. For this exercise, those adjectives were used plus three other pairs that echoed them; respectively; they are Decisive-Indecisive; Expensive-Cheap; Industrious-Lazy. The eight items were ranked on the mean ratings shown in Table 17. Essentially, the items for which arbitrary coherence appears all tend to be lower in rank on each of these attribute pairs, so they are viewed, relatively, as weak/indecisive, bad/cheap, and passive/lazy. That generalization is not perfect, since the Teleflora flowers are third on Decisive and fourth on Good, while the Wallet is rated Expensive and the Necklace is Active. Perhaps though, being relatively weak/indecisive, bad/cheap, and passive/lazy assists in generating the effect. 
TABLE 16

RANKING OF ITEMS ON MEAN SEVEN-POINT SCALE VALUES

\begin{tabular}{|c|c|c|c|c|c|c|}
\hline Rank & Strong-Weak & $\begin{array}{c}\text { Decisive- } \\
\text { Indecisive }\end{array}$ & Good-Bad & $\begin{array}{c}\text { Expensive- } \\
\text { Cheap }\end{array}$ & $\begin{array}{c}\text { Active- } \\
\text { Passive }\end{array}$ & $\begin{array}{c}\text { Industrious- } \\
\text { Lazy }\end{array}$ \\
\hline 1 & Soap & Bowl & Soap & Syrup & Soap & Soap \\
\hline 2 & Bowl & Soap & Bowl & Bowl & [Necklace] & Bowl \\
\hline 3 & Dr. Scholl's & [Teleflora] & L.Carroll & [Wallet] & Dr. Scholl's & Syrup \\
\hline 4 & Syrup & Dr. Scholl's & [Teleflora] & [Necklace] & Bowl & Dr. Scholl's \\
\hline 5 & [Necklace] & L.Carroll & Dr. Scholl's & Dr. Scholl's & L.Carroll & [Wallet] \\
\hline 6 & L.Carroll & [Necklace] & [Necklace] & L.Carroll & Syrup & [Necklace] \\
\hline 7 & [Teleflora] & Syrup & Syrup & [Teleflora] & [Wallet] & L.Carroll \\
\hline 8 & [Wallet] & [Wallet] & [Wallet] & Soap & [Teleflora] & [Teleflora] \\
\hline
\end{tabular}

Note: items in bold and bracket indicate the Arbitrary Coherence effect is present

TABLE 17

MEAN VALUES FOR EACH ITEM ON SEVEN-POINT SCALE

\begin{tabular}{|l|c|c|c|c|c|c|}
\hline & $\begin{array}{c}\text { Strong(7) } \\
\text { Weak (1) }\end{array}$ & $\begin{array}{c}\text { Decisive(7) } \\
\text { Indecisive(1) }\end{array}$ & $\begin{array}{c}\text { Good(7) } \\
\text { Bad (1) }\end{array}$ & $\begin{array}{c}\text { Expensive(7) } \\
\text { Cheap (1) }\end{array}$ & $\begin{array}{c}\text { Active(7) } \\
\text { Passive(1) }\end{array}$ & $\begin{array}{c}\text { Industrious(7) } \\
\text { Lazy (1) }\end{array}$ \\
\hline Teleflora & 4.72 & 4.98 & 5.44 & 4.44 & 4.24 & 4.42 \\
\hline Dr. Scholl's & 5.20 & 4.84 & 5.33 & 4.61 & 4.59 & 4.82 \\
\hline Syrup & 5.10 & 4.67 & 4.92 & 5.29 & 4.53 & 4.88 \\
\hline Soap & 5.72 & 5.08 & 5.80 & 4.22 & 5.34 & 5.42 \\
\hline Wallet & 4.64 & 4.44 & 4.56 & 4.76 & 4.26 & 4.78 \\
\hline Bowl & 5.64 & 5.10 & 5.54 & 5.26 & 4.58 & 5.34 \\
\hline Necklace & 4.92 & 4.72 & 5.24 & 4.66 & 4.66 & 4.76 \\
\hline L.Carroll & 4.92 & 4.80 & 5.52 & 4.46 & 4.56 & 4.60 \\
\hline
\end{tabular}

AC 4 Research Questions Answered:

1. Is the arbitrary coherence phenomenon found in a national sample of adults questioned about each of the eight items used in prior research?

The best answer is "no." Arbitrary coherence is clearly present in only two of eight items, weakly in a third. But over the quartiles, the average price willing to pay appears to randomly shift for all but the Teleflora, which rises consistently.

2. What happens if the eight items in the Sets are broken up and each article is tested individually? Apparently, the context of the sets matters in some nonspecific way. The reasonably strong effects seen with Set 1 items in prior research were lessened when the items were shown alone, and two of the items in Set 2, Necklace and the Wallet, were strengthened. Arbitrary coherence was not seen in Set 2 in two prior studies.

3. Does a semantic differential measurement of how each item is perceived shed light on the differences between items for which arbitrary coherence reliably appears and those for which it does not?

The items for which arbitrary coherence appears generally tend to be lower in rank on each of these attributes, so they are viewed, relatively, as weak/indecisive, bad/cheap, and passive/lazy. The only item for which arbitrary coherence reliably appears is Teleflora, though not statistically significant in AC3, likely due to small base sizes. It is "middling" on the Semantic Differential 
and relatively weak, cheap, passive, and lazy. Other items were as well, so no conclusion about items for which arbitrary coherence reliably appears are possible.

\section{Study \#5 (AC5) - Arbitrary Coherence Versus Monadic Testing}

In addition to measuring the arbitrary coherence effect on an item from the original Ariely study, the objective of this final study was to examine the extent a price-demand curve based on AC results parallels one derived from more tradition monadic testing. Marketing researchers sometimes use monadic testing to determine price sensitivity and create a demand curve. If $\mathrm{AC}$ creates a similar demand curve, it might be a useful tool to more efficiently (i.e., fewer subjects, less expensive) create that curve.

This study is comprised of two groups which are compared to address the objectives. Group 1 completes a standard three question $\mathrm{AC}$ task, followed by a monadic purchase intent (PI) question including price, with the group split by four price points. Group 2 is the reverse, specifically the purchase intent question is first followed by the standard 3 question arbitrary coherence task. For this study, an item was needed with an ambiguous price and could easily be used by anyone, men or by women, young or old, etc. The Belgian chocolates used in the original Ariely article was selected.

The sample consists of 401 subjects (not the same sample as AC4) from across the United States. All were prescreened as having enjoyed chocolate in some form "recently." Statistical testing shows that the two groups do not differ in terms of age, sex, race, education, or geographic distributions $(\mathrm{p}>.05)$. The highest percentages are older, between 50 and 69. Most, about seven in 10, are female. The majority, more than eight in 10, are White. Overall, 5\% indicated they were Hispanic. The highest percent, just over a third, had some college, with about a fourth having a college degree. The respondents were fairly evenly split between Northeast, Midwest, South and West.

A Word version of the complete online questionnaire can be found in Appendices 5 and 6 . After determining demographics, a question about whether or not the subject has enjoyed chocolate recently was asked in a blinded fashion to make certain only those who possibly would be interested in the Belgian Chocolates were questioned.

In Group 1, two hundred (200) were asked about a box of 24 Fine Belgian Chocolates, using the three arbitrary coherence questions with the last two digits of the telephone number used to determine the arbitrary anchor. Then, each respondent was randomly assigned to one of four price subgroups $(\$ 12.50$, $\$ 37.50, \$ 62.50, \$ 87.50)$ and asked purchase intent (PI) for the same item. Price points were selected by taking the midpoints of the quartiles between zero and 100, after ensuring that some Fine Belgian Chocolates actually do sell for those amounts.

In Group 2, two hundred one (201) were randomly assigned to the four price points first. Each saw the same picture and description of the Belgian Chocolates used for Group 1, but were asked purchase intent (PI) using the traditional scale (Definitely Would Buy, Probably Would Buy, Might or Might Not Buy, Probably Would Not Buy, Definitely Would Not Buy). They were then asked the same arbitrary coherence questions as asked in Group 1.

\section{Summary of Arbitrary Coherence Results for AC5}

Given that the arbitrary coherence effect is often not found, it seemed reasonable to first learn if it could be found in either of these groups. The effect was found in both groups. In Group 1 (AC task first) the correlation between the arbitrary number derived from the telephone number and the Willingness to Pay (WTP) amount is 0.31 (statistically significantly above zero) versus Ariely's .491. There is only one WTP reversal as one goes up the arbitrary telephone dollar quintiles, and that is at the highest level. 
TABLE 18

GROUPS 1 BELGIAN CHOCOLATE RESULTS WHEN AC TASK IS FIRST

\begin{tabular}{|c|c|c|c|c|c|c|}
\hline & \multicolumn{5}{|c|}{ \$Phone\# for AC5 and \$SSN for Ariely } & \\
\hline Products & Quintile 1 & Quintile 2 & Quintile 3 & Quintile 4 & Quintile 5 & $\begin{array}{c}\text { Corre- } \\
\text { lation }\end{array}$ \\
\hline $\begin{array}{c}\text { AC5 Belgian } \\
\text { Chocolates Avg. } \\
\text { WTP (n=200) }\end{array}$ & $\$ 12.82$ & $\$ 18.15$ & $\$ 21.41$ & $\$ 30.08$ & $\$ 28.03$ & $\begin{array}{c}.310 \\
\mathrm{p} \leq 0.05\end{array}$ \\
\hline $\begin{array}{c}\text { Ariely Belgian } \\
\text { Chocolates Avg. } \\
\text { WTP (n=55) }\end{array}$ & $\$ 9.55$ & $\$ 10.64$ & $\$ 12.45$ & $\$ 13.27$ & $\$ 20.64$ & $\begin{array}{c}.419 \\
\mathrm{p}=.0013\end{array}$ \\
\hline
\end{tabular}

Similarly, the effect is found in Group 2, when the AC questions are asked after presenting one of the four prices and asking purchase intent. The effect is lessened, however, with a correlation of .20 and two reversals at the high end of the arbitrary price quintiles.

TABLE 19

GROUPS 2 BELGIAN CHOCOLATE RESULTS WHEN AC TASK IS SECOND

\begin{tabular}{|c|c|c|c|c|c|c|}
\hline & \multicolumn{5}{|c|}{$\begin{array}{l}\text { Last Two Digits or Telephone Number Corresponding to the } \\
\text { Monadic Prices }\end{array}$} & \multirow[b]{2}{*}{ Correl. } \\
\hline & 0 to $\$ 12$ & $\$ 13$ to $\$ 37$ & $\$ 38$ to $\$ 62$ & $\$ 63$ to $\$ 87$ & $\$ 88+$ & \\
\hline Average WTP & $\$ 14.13$ & $\$ 21.92$ & $\$ 33.92$ & $\$ 29.64$ & $\$ 29.44$ & $\begin{array}{c}0.20^{*} \\
p<0.05\end{array}$ \\
\hline
\end{tabular}

It appears that the lower stated prices in the purchase intent question had little effect on the lower quintiles, but restricted reactions to the higher quintiles. Seeing $\$ 87.50$ in a purchase intent question and then being asked for a maximum bid may have biased those with arbitrary scores $\geq \$ 88$.

\section{Summary of Purchase Intent Results}

Table 20 shows the results of the purchase intent (PI) questions for each group. An examination of the sum of those who said they definitely or probably would buy, ("top two buy" scores, or T2B scores), shows the order made little difference. In three of the four instances, the T2B scores are statistically the same in Groups 1 and 2. For the highest price, it is directionally different, suggesting completing the AC task first pulled interest down at the highest price. 
TABLE 20

PURCHASE INTENT QUESTION RESULTS BY PRICE POINTS AND GROUPS

\begin{tabular}{|c|c|c|c|c|c|c|c|c|}
\hline & \multicolumn{2}{|c|}{$\$ 12.50$} & \multicolumn{2}{c|}{$\$ 37.50$} & \multicolumn{2}{c|}{$\$ 62.50$} & \multicolumn{2}{c|}{$\$ 87.50$} \\
\hline & Grp 1 & Grp 2 & Grp 1 & Grp 2 & Grp 1 & Grp 2 & Grp 1 & Grp 2 \\
\hline Base & 50 & 50 & 50 & 50 & 50 & 51 & 50 & 50 \\
\hline Definitely buy & $26 \%$ & $22 \%$ & $8 \%$ & $18 \%$ & $8 \%$ & $6 \%$ & $2 \%$ & $14 \%$ \\
\hline Probably buy & $30 \%$ & $20 \%$ & $14 \%$ & $16 \%$ & $6 \%$ & $12 \%$ & $4 \%$ & $4 \%$ \\
\hline Might or might not & $16 \%$ & $32 \%$ & $16 \%$ & $22 \%$ & $18 \%$ & $20 \%$ & $6 \%$ & $20 \%$ \\
\hline Probably not buy & $10 \%$ & $14 \%$ & $32 \%$ & $24 \%$ & $16 \%$ & $18 \%$ & $20 \%$ & $14 \%$ \\
\hline Definitely not buy & $18 \%$ & $2 \%$ & $30 \%$ & $20 \%$ & $52 \%$ & $45 \%$ & $68 \%$ & $48 \%$ \\
\hline Total & $100 \%$ & $100 \%$ & $100 \%$ & $100 \%$ & $100 \%$ & $100 \%$ & $100 \%$ & $100 \%$ \\
\hline Definitely+Probably & $56 \%$ & $52 \%$ & $22 \%$ & $34 \%$ & $14 \%$ & $18 \%$ & $6 \%$ & $18 \%$ \\
\hline
\end{tabular}

One of the objectives of this final study was to examine the extent a demand curve based on AC results parallels one derived from more tradition monadic testing. Based on the results shown in Figures 2 and 3, it looks quite promising that an $\mathrm{AC}$ task can be employed to create a price-demand curve. Figure 2 is a graph of the percentages of respondents willing to pay the price range listed on the $\mathrm{x}$-axis. In Figure 3 , the same curve is shown, but with only the four price points (plus $\geq \$ 88$ ) presented to Group 2 respondents. The curves are quite similar. It appears that if a product being tested is susceptible to arbitrary coherence, then the results would be reliable for creating a price demand curve.

The regression lines can be interpreted in the following manner. In Figure 2, for each $\$ 1$ increase in price, the percentage of those willing to buy at that price drops by .284 times the $\log$ of the price. The regression is only valid over the data range of $\$ 0.00$ to $\$ 99.00$ (technically cannot be extrapolated beyond that range). In Figure 3, for each $\$ 1$ increase in price, the percentage of those willing to buy at that price drops by .175 times the log of the price. From visual inspection of both graphs, the AC test shown in Figure 2 appears to provide a more reliable price-demand curve than the monadic price test shown in Figure 3.

FIGURE 2

\section{PRICE DEMAND CURVE FROM ARBITRARY COHERENCE DATA (GROUP 1)}

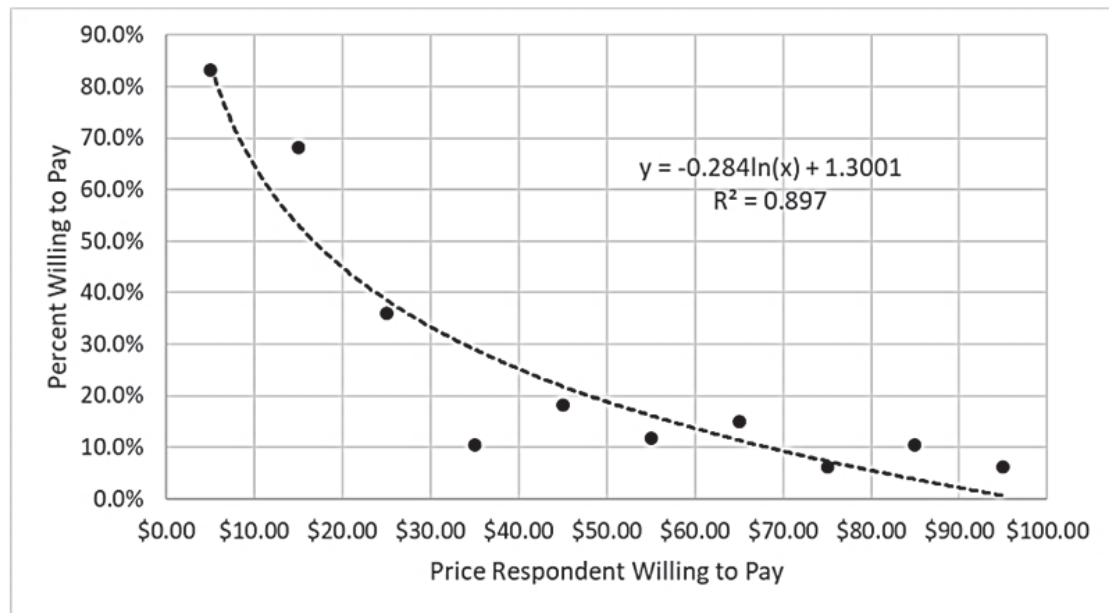

116 American Journal of Management Vol. 20(1) 2020 
FIGURE 3

\section{PRICE DEMAND CURVE FROM PURCHASE INTENT DATA (GROUP 2)}

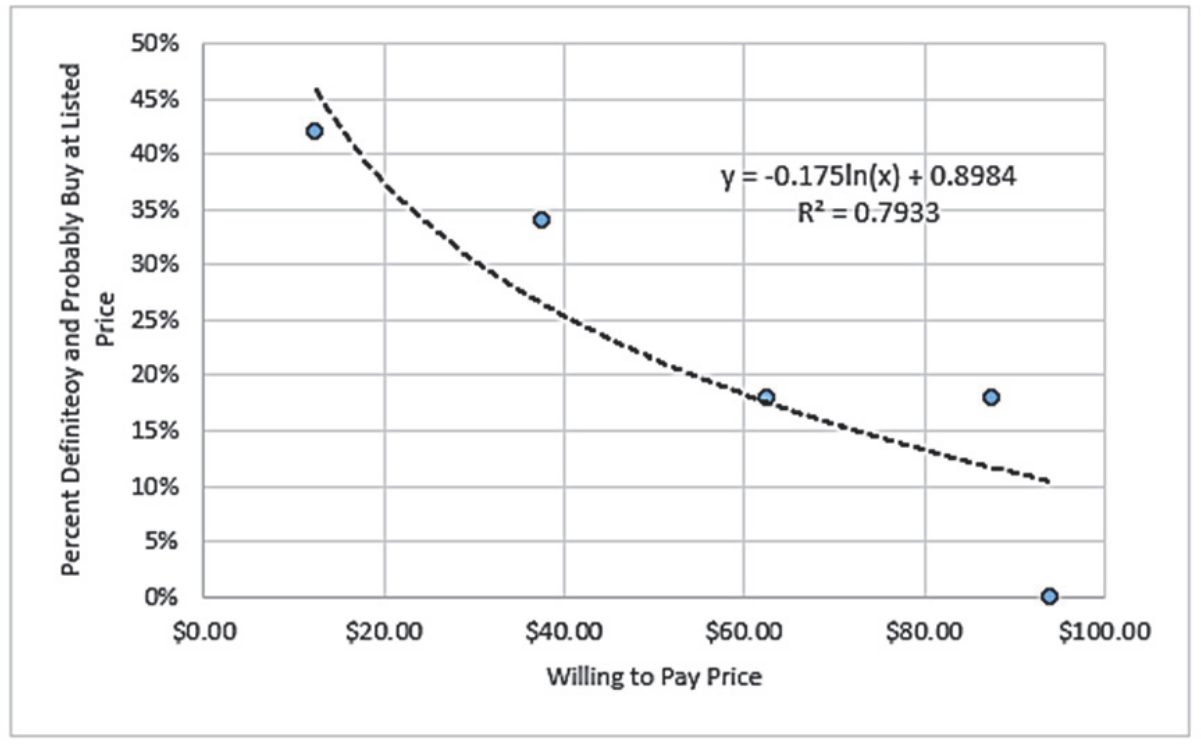

Summary of AC5 Results

Under the carefully specified conditions created for this study the AC phenomenon is clearly present. Also, of interest is that whether the AC task was first or second had little effect on the results of the PI task, which were very similar regardless. The exception was at the highest price level asked in PI (\$87.50), in which the AC task depressed the percent willing to buy. This may have been an anchoring effect, since most of the arbitrary numbers were lower than that price point.

In the reverse order, half saw PI prices first that were lower than $\$ 63$, so there appears to be an anchoring effect that way as well. The AC correlation was lessened, with the middle price point higher than when the $\mathrm{AC}$ task was first and those getting the $\mathrm{AC}$ task second indicating lower prices in the higher arbitrary number quintiles.

\section{Observation on a Random Number Distribution}

The original work by Ariely used the last two digits of the social security number as the random number which seems quite reasonable. With the more recent privacy concerns around social security numbers, it seemed reasonable to use the last two digits of a person's telephone number as the random number for testing purposes. While creating the tables for AC5 it was observed that the random numbers were not quite so randomly distributed. As shown in Figure 4, as the decile range increased the frequency of occurrence decreased.

This phenomenon does not adversely affect the results of AC4 or AC5 since any random number is sufficient for the study of arbitrary coherence. However, if this phenomenon is not an aberration, then research requiring a uniform distribution of random numbers using a telephone number may need to sample in such a way as to obtain a more uniform distribution of respondents. 


\section{FIGURE 4 \\ RANDOM NUMBER DISTRIBUTION FROM AC5 STUDY}

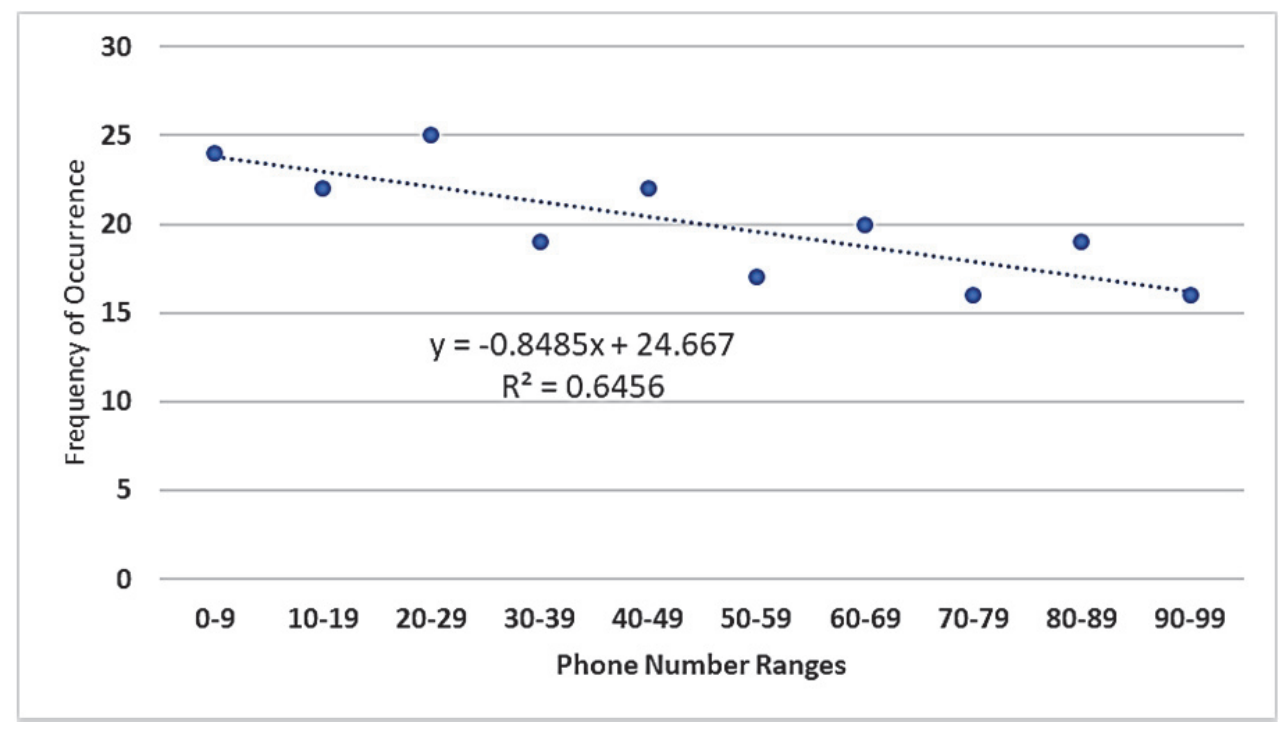

It would be interesting to determine if the last two digits of one's telephone number is not as random as one would expect or if respondents are also reluctant to give their actual numbers. If respondents are making up a number, it seems remarkable that the distribution is so linearly predicable. It is unlikely however, that any more than a small percentage of people willing to cooperate in an interview of this nature would deliberately mislead. Even more amazing is that numbers beginning with 2, 4, 6 and 8 consistently deviate positively from the regression line and numbers beginning with $1,3,5$ and 7 consistently deviate negatively from the regression line.

\section{CONCLUSIONS}

There are two aspects of arbitrary coherence. The first is that the anchor, which everyone knows is arbitrary, influences the judgment of subjects in the selection of a starting point when asked about pricing in an ambiguous situation. As noted, in our three-question work, we found (along with Wilson, 1996) that some processing of the arbitrary number must occur to see the influence. Hence, no effect when "question two," the purchase decision, is not asked.

There are two hypotheses for why the arbitrary number has this effect. One is the "reach back" hypothesis proposed by Kahnemann. Subjects need something to think of when asked the third question (the auction question) and so they reach back for a handy recent number. The other is the "imprinting" hypothesis of Ariely et. al., similar to the "carry forward" alternative Wilson discusses. The idea is simply that since the arbitrary number is still in mind, it has an influence.

The second aspect of arbitrary coherence is sequentiality, or coherence. The first WTP influences all subsequent ones. However, the three-question demonstration does not show sequential or coherent impact. In it, each subject is exposed to a single arbitrary number and creates a single judgment. If the anchoring effect is not present, then there is no "coherence" using this method. Ariely et. al. did find evidence for sequential impact in the other five "annoying sound" experiments they conducted, since in those the subjects experienced repeated exposures to sounds of varying durations. However, the "arbitrary coherence" shown in their Experiment 1 and (where it appears) in our work only demonstrates an anchoring effect. Coherence (when it is found) is an artifact produced by anchoring across a group of subjects.

While the "coherence" in arbitrary coherence is weak or nonexistent for some items tested, the "arbitrary" reaction, i.e., anchoring, is present. As noted previously, data were examined across the first 
four studies to see if the highest quartile gave a higher WTP than the lowest. This did occur in 19 of 24 instances. The fact that 19 of 24 instances show an impact of the arbitrary value in raising WTP, most by more than five dollars, suggest the anchor influenced the respondent's willing to pay price.

The Semantic Differential results are challenging to interpret. While being the strongest, best, and most active is not conducive to arbitrary coherence or consistency in anchoring, the conclusion is based on relative ranks within these eight items, and suffers that limitation. Finally, despite its limitations, it appears from AC5 that the three arbitrary coherence questions can be quite useful in exploring the pricedemand relationship, one that is often challenging in the development of new products.

\section{REFERENCES}

Ariely, D., Loewenstein, G., \& Prelac, D. (2003, February). Coherent Arbitrariness: Stable demand curves without stable preferences. The Quarterly Journal of Economics.

Ariel, D. (2008). Predictably Irrational. Harper Collins, NY, NY.

Fudenberg, D., Levine, D. K., \& Maniadis, Z. (2015, June 16). Reexamining Coherent Arbitrariness for the Evaluation of Common Goods and Simple Lotteries. Published online at ResearchGate.

Kahneman, D. (2010). Thinking, Fast and Slow. Farrar, Straus and Giroux, New York, NY.

Osgood, C., Suci, G., \& Tannenbaum, P. (1957). The Measurement of Meaning. University of Illinois Press, Champaign, IL.

Pothier, D. D., Mangal, T., Loizou, P., \& Mason, K. A. (2009). Arbitrary coherence in theoretical decision making about surgical training: the effect of irrelevant subliminal anchoring. Journal of Surgical Education, 66(3), 129-131.

Poundstone, W. (2010). Priceless. Hill and Wang, a division of Farrar, Straus, and Giroux, NY, NY.

Scott, P. J., \& Lazier, C. (2012). Consumer house price judgements: new evidence of anchoring and arbitrary coherence. Journal of Property Research, 29(1), 49-68.

Tversky, A., \& Kahneman, D. (1974). Judgment under Uncertainty: Heuristics and Biases. Science, New Series, 185(4157).

Unknown. (2017). Scaling: Semantic Differential. Retrieved October 17, 2017, from http://psc.dss.ucdavis.edu/sommerb/sommerdemo/scaling/semdiff.htm.

Wilson, T.D., Houston, C.E., Etling, K.M., \& Brekke, N. (1996). A New Look at Anchoring Effects: Anchoring and Its Antecedents. Journal of Experimental Psychology: General, 125(4), 387-402. 
IMAGES FOR ITEM SET 1 (AC1 AND AC3)

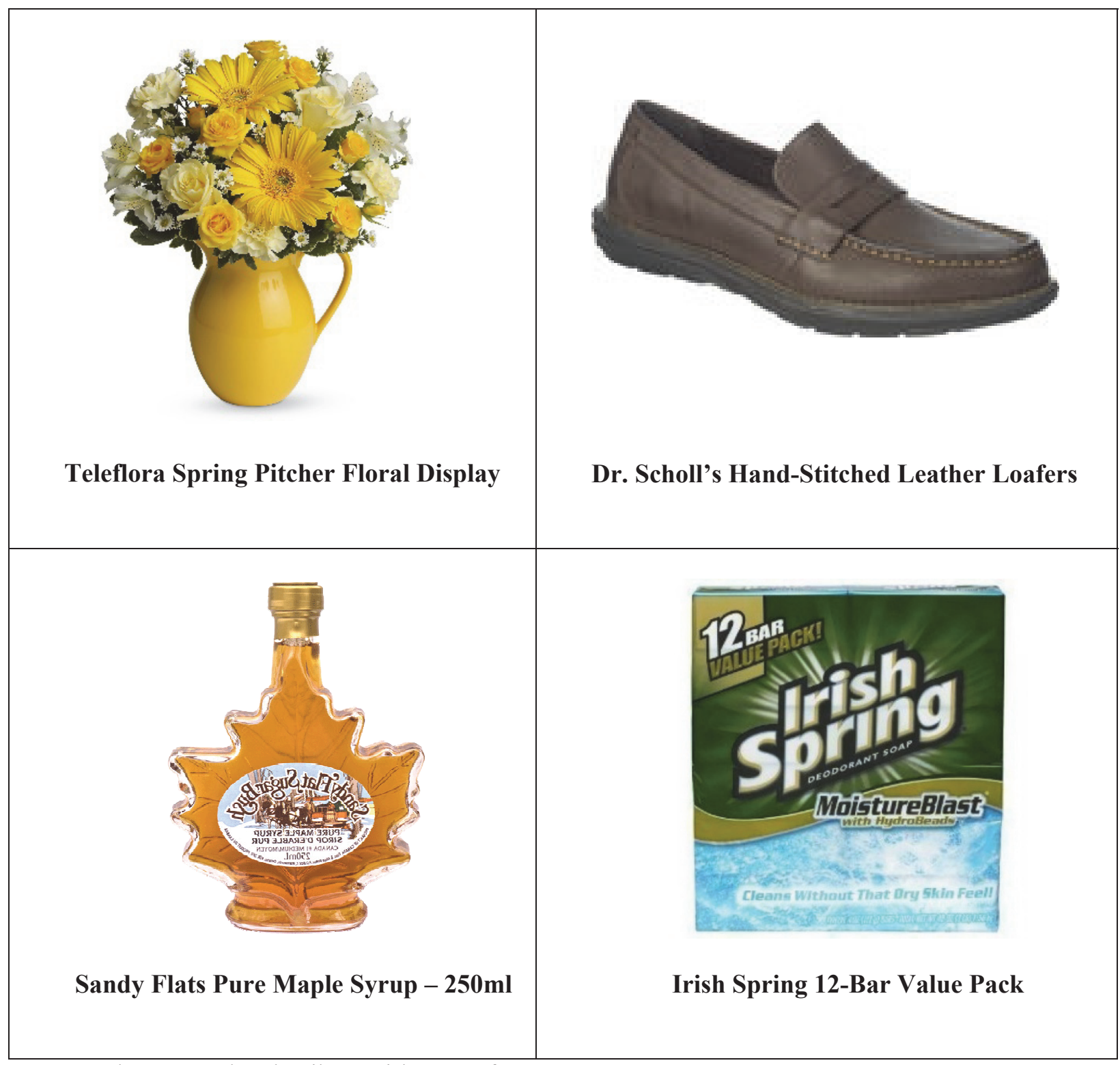

Note: Maple syrup replaced Bailey's Irish Crème for AC3. 


\section{APPENDIX 2}

\section{QUESTION SURVEY}

Thank you in advance for your help with this project. There are three questions. When the project is complete, we will be happy to share the results with you.

A. In column A, next to each of the four items on the list below, please enter the last two digits of you Social Security number (SS\#) as if it were a price in dollars.

For example, if your SS\# is 678-54-9876, you would put \$76. If it is 123-45-0001, you would enter $\$ 01$.

B. In column B, indicate if you would be willing to pay that amount for the item by writing in a $\mathrm{Y}$ for "yes" or an N for "no".

C. In column $\mathrm{C}$, pretend there is an auction for the item. In whole dollars, write in the maximum amount you would be willing to pay for it.

\begin{tabular}{|l|l|l|l|}
\hline Item & A. SS\# as \$ & $\begin{array}{c}\text { B. Willing to } \\
\text { Purchase for that } \\
\text { price? (Y or N) }\end{array}$ & $\begin{array}{c}\text { C. Max willing } \\
\text { to pay: }\end{array}$ \\
\hline Item 1 & & & \\
\hline Item 2 & & & \\
\hline Item 3 & & & \\
\hline Item 4 & & & \\
\hline
\end{tabular}


IMAGES FOR ITEM ST 2 (AC2 AND AC3)

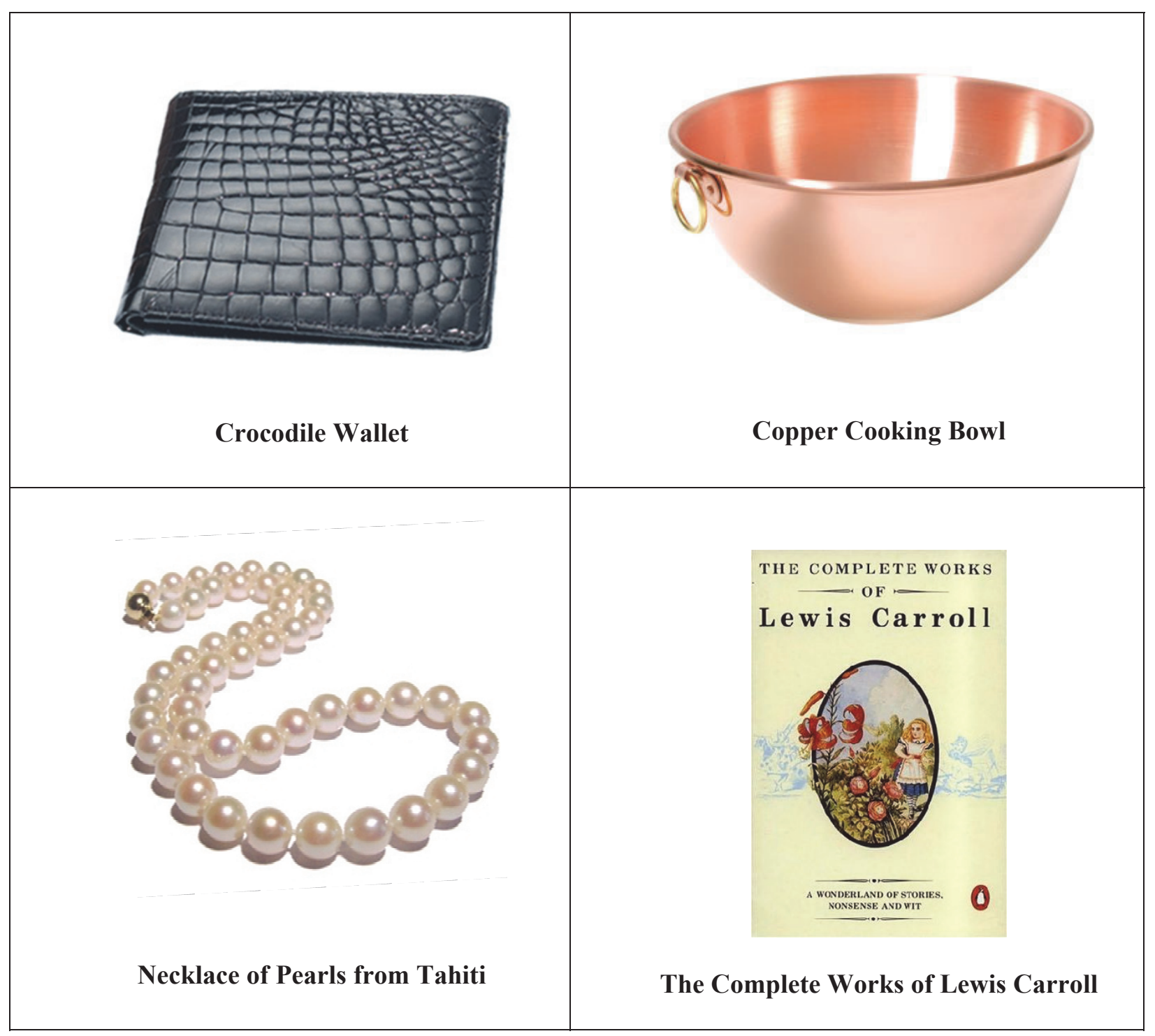




\section{APPENDIX 4}

\section{QUESTION SURVEY}

Thank you in advance for your help with this project. There are two questions. When the project is complete, we will be happy to share the results with you.

A. In column A, next to each of the four items on the list below, please enter the last two digits of you Social Security number (SS\#) as if it were a price in dollars.

B. For example, if your SS\# is 678-54-9876, you would put $\$ 76$. If it is 123-45-0001, you would enter $\$ 01$.

C. In column $\mathrm{C}$, pretend there is an auction for the item. In whole dollars, write in the maximum amount you would be willing to pay for it.

\begin{tabular}{|l|l|l|}
\hline Item & A. SS\# as \$ & $\begin{array}{c}\text { B. Max willing } \\
\text { to pay: }\end{array}$ \\
\hline Item 1 & & \\
\hline Item 2 & & \\
\hline Item 3 & & \\
\hline Item 4 & & \\
\end{tabular}




\section{APPENDIX 5}

\section{PART 1 OF QUESTIONNAIRE FOR AC5}

1. How old were you on your last birthday?

2. Please select your gender:

Female

Male

3. What is your primary U.S. state of residence?

[Drop down list.]

4. To ensure representation, please check the box best representing your race.

Black/African American

Mixed racial background

White/Caucasian

Prefer Not to Answer

5. Are you Hispanic?

Yes

No

6. Please select your level of education:

Some High School or Less

High School Graduate

Some College

4 Year College/University Degree

Some Graduate School

Master's Degree or Above

Prefer Not to Answer

Randomize responses to Q.7. All must say Chocolate to continue.

7. Please select which of these foods you have enjoyed recently:

Chocolate

Jalapenos

Hamburgers

Ice Cream

Pasta

[Illogical responses: if respondent said would pay $\$ x$ at $A C Q .2$ and max bid $<\$ x$ at $A C Q 3$, OR would not pay $\$ x$ at $A C Q .2$ and max bid $>\$ x$ at $A C Q 3$, point out and re-ask $A C Q .2$ and $A C Q .3$. 


\section{APPENDIX 6}

PART 2 OF QUESTIONNAIRE FOR AC5

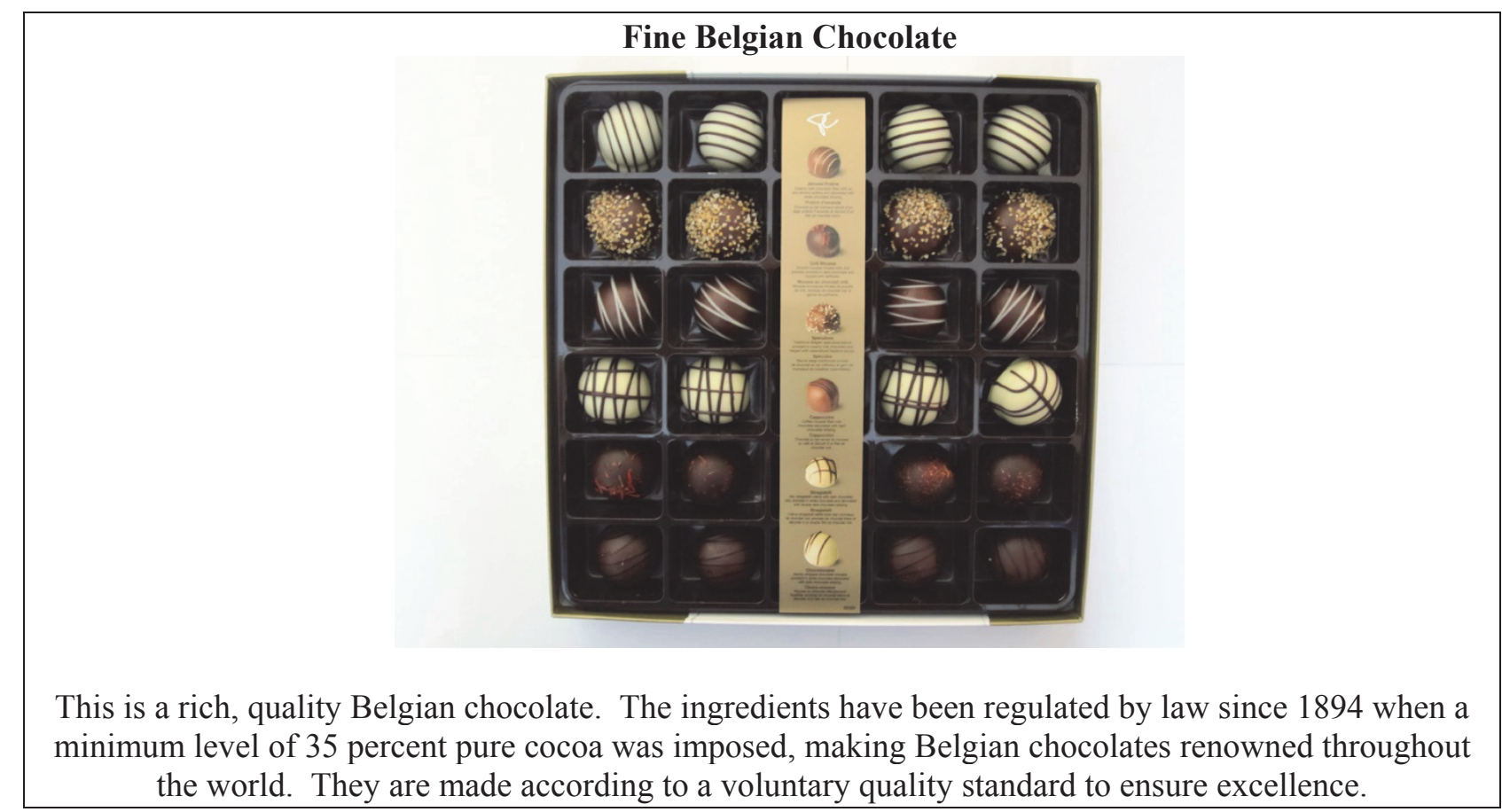

Each question appeared on a separate page. The product and description stayed in view the entire time.

\section{Ask of Group 1 first, Group 2 second}

AC Q1. Please write the last two digits of your primary telephone number as if it were a price in dollars. For example, if your primary telephone number is 555-721-1701, you would put $\$ 01$. If it is 555-7210171, you would enter $\$ 71$.

AC Q2. Please indicate if you would be willing to pay the dollar amount you just listed for the item in the picture.

AC Q3. Pretend there is an auction for the pictured item. In whole dollars, write in the maximum amount you would be willing to pay for it.

\section{Ask of Group 1 second, Group 2 first}

PI Q1.How likely are you to buy the box of Belgian chocolates as shown. That is, would you say you... $[N=50$ for each of 4 prices for a box of 24 --\$12.50; \$37.50; \$62.50; 87.50. Random assignment. $]$

Definitely would buy it

Probably would buy it

Might or might not buy it

Probably would not buy it

Definitely would not buy it 